\title{
ESTIMATING CONTRIBUTION OF WATER FLOW COMPONENTS TO KAMENG RIVER BASIN USING HYDROLOGICAL MODELLING
}

\author{
Siddharth Arora ${ }^{1, *}$, Anil V. Kulkarni ${ }^{1}$, Prosenjit Ghosh ${ }^{1}$, S.K. Satheesh ${ }^{1}$ \\ ${ }^{1}$ Divecha Centre for Climate Change, Indian Institute of Science, Bengaluru, India (siddhartha1, anilkulkarni, pghosh, \\ satheesh)@iisc.ac.in; siddarora.civil@gmail.com
}

KEY WORDS: VIC Hydrological Model, Meltwater Contribution, Kameng River, Hydrograph Separation, Flow Components, Himalayan Cryosphere

\begin{abstract}
:
The Himalayas, also known as third pole of the Earth feed some of the major rivers of the world viz. Ganga, Indus, Brahmaputra etc. The accurate assessment of water resources in eastern Himalayas is very important for respective policy makers. The detailed assessment of water resources and hydrological cycle component are very critical for attaining United Nations sustainable development goals (SDGs) such as affordable and clean energy, clean water and sanitation and building resilient infrastructure This study focuses on Kameng river basin, estimating the melt water \& its contribution to the total discharge of the river. A 3-layer VIC model coupled with energy balance algorithm is used to estimate the patterns of melt and discharge profile in the region. Net contribution of melt water to the river were estimated to be about $18 \%$ during peak melt season in upper catchments. With advancement in technology, acquiring meteorological data via remote sensing has become more accurate $\&$ of high resolution. This data is one of the major inputs of the model. With accurate forecasting of these parameters, multipurpose hydropower projects in these regions can plan well in advance thus playing a major role in Integrated Water Resource Management. In current study the coefficient of determination \& Nash-Sutcliffe efficiency were calculated to be $0.82 \& 0.71$ respectively. With increasing population in the region, any substantial change in the streamflow will have consequences unknown as of now, thus making this study a necessity \& need of hour.
\end{abstract}

\section{INTRODUCTION}

The Himalayan river systems such as Ganga, Indus, Brahmaputra etc. ensure water supply to 1.3 billion people (Brown M.E. et al., 2010) all round the year in territories of India, Pakistan, Tibet, China and Myanmar. The catchments of these Himalayan rivers, in particular in the mountainous regions are now witnessing changes due to alterations in demographics, geomorphological \& extreme weather events. The assessment \& monitoring of hydrometeorological parameters in these regions encounter several difficulties due to ruggedness and remoteness of the area (Thakur et al., 2019; Dimri et al., 2020). The water availability in these rivers is at risk in a changing climate scenario (Immerzeel \& Bierkens, 2012). The UN Sustainable Development Goals (SDG's) as developed, particularly focussing on affordable renewable energy, climate action, availability of clean water and sanitation are in direct conjunction with availability of fresh surface water, stored water in snow cover \& glacial ice in the river basins of Himalayan region. The Eastern Himalayan region with respect to the hydrological systems are very sensitive to change in climate patterns, both on seasonal \& long term basis (Chiphang, Bandyopadhyay, \& Bhadra, 2020). Several Hydropower projects are under implementation stages in the region, owing to high hydropower potential. Along with that increasing population due to development works in the region is alleviating the demand for water, thus straining the water resources $\&$ imposing a direct impact on water budgeting \& availability. These concerns have made the eastern Himalayan region a focus of research in recent times.
Hydrological modelling is one of the many ways which can be used to efficiently quantify the hydrological components in long term study. The modelling represents the natural processes as a set of mathematical equations which governs the water balance of the catchment, with a fundamental objective to provide reliable information for integrated water resource management. Spatially distributed models such as AVSWAT, MIKE-SHE \& HECHMS, developed using physical principles of hydrology are available. In present study Variable Infiltration Capacity (VIC) model has been used. It's a semi-distributed, physically based macroscale hydrological model using energy balance algorithm. A river routing coupled with VIC allows for comparison between observed discharge at gauging stations \& model derived discharge. Further details of the VIC model can be found in Liang (1994); Liang et. al, (1994); Liang et al. (1996); Lettenmaier (2001).

The remote sensing \& GIS based techniques are required to be used to understand physical characteristics such as meteorological parameters, given limited availability of data and assess large scale complex spatially \& temporally distributed hydrological processes. Remote Sensing \& GIS offers a potential to observe entire catchments rather than a few select points. Limited availability of the ground data lays the foundation for the data as obtained from Earth Observation (EO) missions coupled with hydrological models to play a significant role in systematic and continuous monitoring of water resources and assessment of water availability in both present and future scenarios. The results as obtained from this study shall be helpful in water resources planning and management as well as to provide a support for further studies.

\footnotetext{
${ }^{*}$ Corresponding author
} 


\section{STUDY AREA}

The appropriate geographical representation of a study area in water resource management is the river basin. Kameng River basin is the focus in this study. Kameng river originates in State of Arunachal Pradesh near the Indo-Tibet Border, flowing through East Kameng, West Kameng districts of Arunachal Pradesh and Sonitpur district of Assam (where its known as "Jia Bharali") before draining into the mighty Brahmaputra River at Tezpur, Assam. The river traverses a distance of approx. $264 \mathrm{~km}$ encompassing a catchment area of 10798.51 sq.km with two major tributaries viz. Dirang Chu \& Tenga joining the river. The study area is boxed in-between $26^{0} 30^{\prime} 0^{\prime \prime} \mathrm{N}$ to $28^{\circ} 0^{\prime} 0^{\prime \prime} \mathrm{N}$ and $92^{\circ} 0^{\prime} 0^{\prime \prime} \mathrm{E}$ to $93^{\circ} 30^{\prime} 0^{\prime \prime} \mathrm{E}$ with elevation ranging from $53 \mathrm{~m}$ at Tezpur to $7000 \mathrm{~m}$ near to Indo-Tibet border, as shown in Figure 1 . The peak discharge during summer monsoon season is approx. 4000 cumec, while minimum in winter is about 140 cumec. The average annual rainfall is $2143 \mathrm{~mm}$, most of which occurs in monsoon season while the temperature is moderate with average peak at $15^{\circ} \mathrm{C}$ in summers \& Average low around $0^{\circ} \mathrm{C}$ in winter. The region is home to 600MW Kameng Hydro Electric Project, managed by NEEPCO, A GoI enterprise.

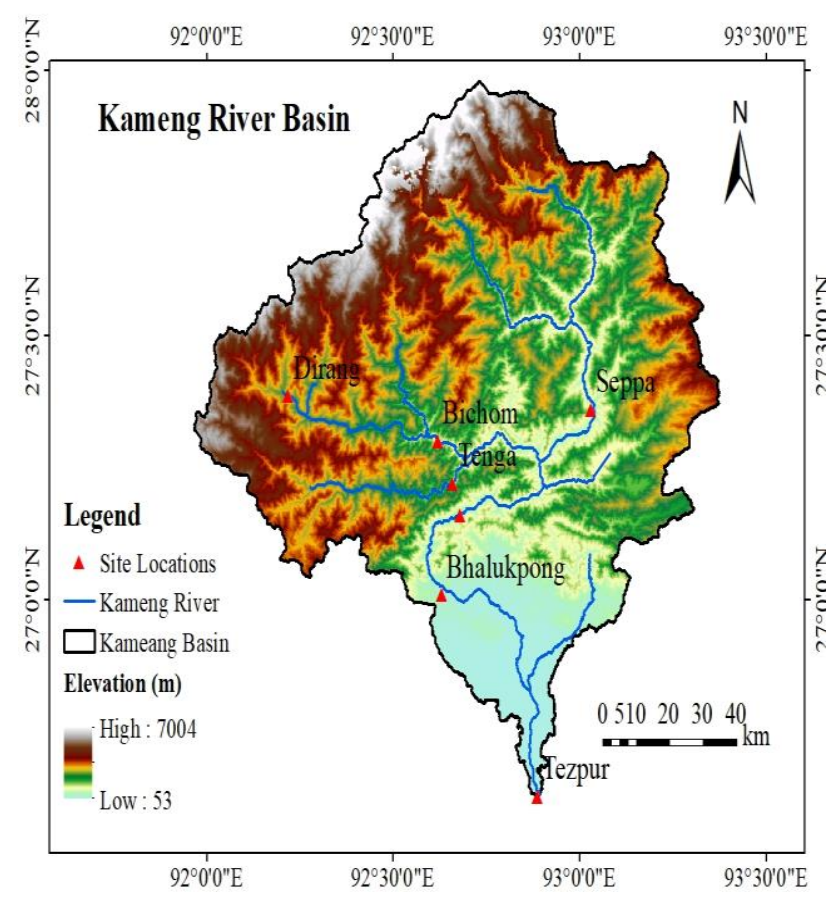

Figure 1. Study Area.

\section{METHODOLOGY}

The methodology was divided into 3 components; Input Generation, Hydrological Modelling \& Hydrograph Separation. The flowchart is shown in Figure 2.

\subsection{Data Inputs}

VIC model requires extensive data as input to accurately model the hydrological regime, as mentioned in Table 1.

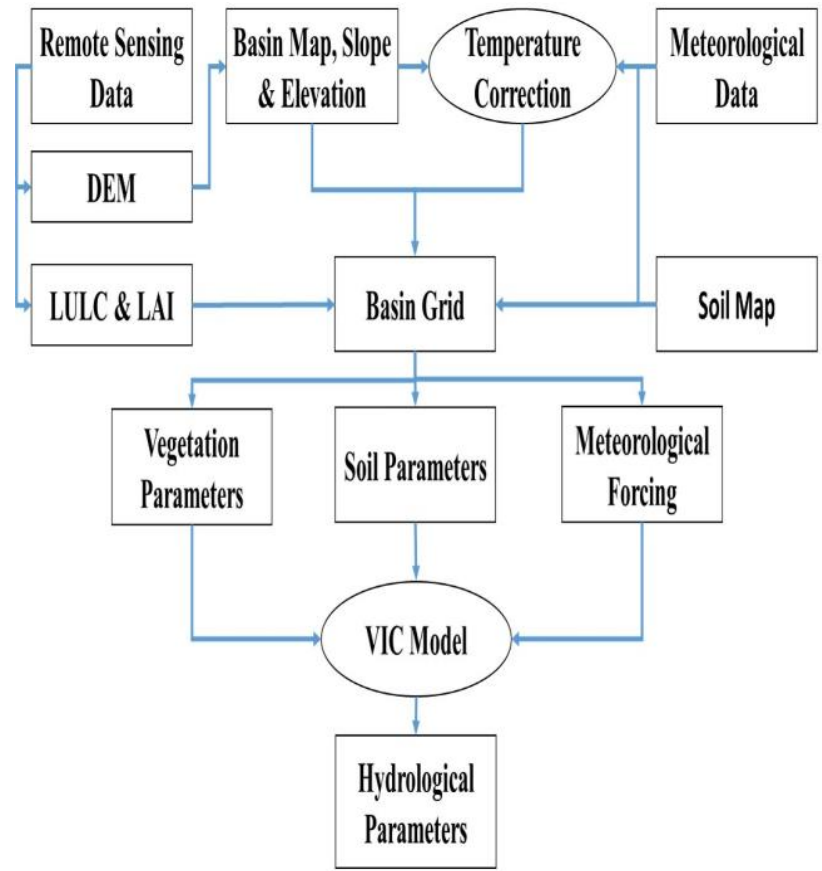

Figure 2. Workflow Chart

\begin{tabular}{|c|c|c|}
\hline Data Type & Source & Resolution \\
\hline $\begin{array}{c}\text { Elevation } \\
\text { Profile (DEM) }\end{array}$ & SRTM & $90 \mathrm{~m}$ \\
\hline Soil Data & FAO & $1: 1,000,000$ \\
\hline $\begin{array}{c}\text { Land Use Land } \\
\text { Cover }\end{array}$ & USGS & $500 \mathrm{~m}$ \\
\hline $\begin{array}{c}\text { Meteorological } \\
\text { Data }\end{array}$ & ERA -5 & $0.25^{0}, 3$ hourly \\
\hline $\begin{array}{c}\text { Hydrological } \\
\text { Data }\end{array}$ & $\begin{array}{c}\text { B\&BBO, CWC, Jal } \\
\text { Shakti Ministry, GoI }\end{array}$ & 2000 onwards \\
\hline
\end{tabular}

TABLE 1. Data Sources

The Meteorological forcing file contains meteorological parameters such as temperature, precipitation $\&$ wind speed are required to force the VIC model. Forcing data files play big role in the model input to produce all the required outputs in full energy balance modes of the model. The meteorological parametres were acquired from ERA-5 gridded data at $0.25^{\circ}$ spatial \& 3-hour temporal resolution from 1979 onwards. The temperature data was corrected at the run-grid level using elevation difference of the ERA Grid \& Run-Grid by applying the standard lapse rate of $6.5^{\circ} \mathrm{C} / 1000 \mathrm{~m}$, as specified in Equation. 1

Where

$$
\begin{aligned}
& \mathrm{T}_{\text {grid }}=\mathrm{T}_{\mathrm{ERA}}-(6.5 / 1000) *\left(\mathrm{ELEV}_{\text {grid }}-\mathrm{ELEV}_{\mathrm{ERA}}\right) \\
& \mathrm{T}_{\text {grid }} \text { - Corrected Temperature of Grid } \\
& \mathrm{T}_{\text {ERA }}-\text { Temperature of ERA5 Grid } \\
& \text { ELEV - Elevation as obtained from DEM }
\end{aligned}
$$

For model calibration \& validation purposes, the discharge data at bhalukpong was obtained from Brahmaputra \& Barak Basin Organisation, Central Water Commission, Ministry of Jal Shakti, Government of India.

The river basin boundary was delineated using $90 \mathrm{~m}$ DEM as obtained from Shuttle Radar Topography Mission (SRTM) \& processing in HEC-GeoHMS tool with outlet being defined at Tezpur, Assam. A grid of resolution $0.025^{\circ}$ was layered over the 
basin shape file as obtained to extract the parameters from various thematic layers as required by VIC model.

Land Use Land Cover (LULC) data was sourced from $0.5 \mathrm{~km}$ MODIS-based Global Land Cover Climatology by USGS Land Cover Institute (Broxton, Zeng, Sulla-Menashe \& Troch, 2014), as shown in Figure 3. The hydrological fluxes are primarily influenced by Leaf Area Index (LAI), derived from MODIS LAI product (Myneni, Knyazikhin \& Park, 2015) at $500 \mathrm{~m}$ spatial resolution. The Soil data as provided by FAO Harmonized World Soil Database v 1.2 has been used

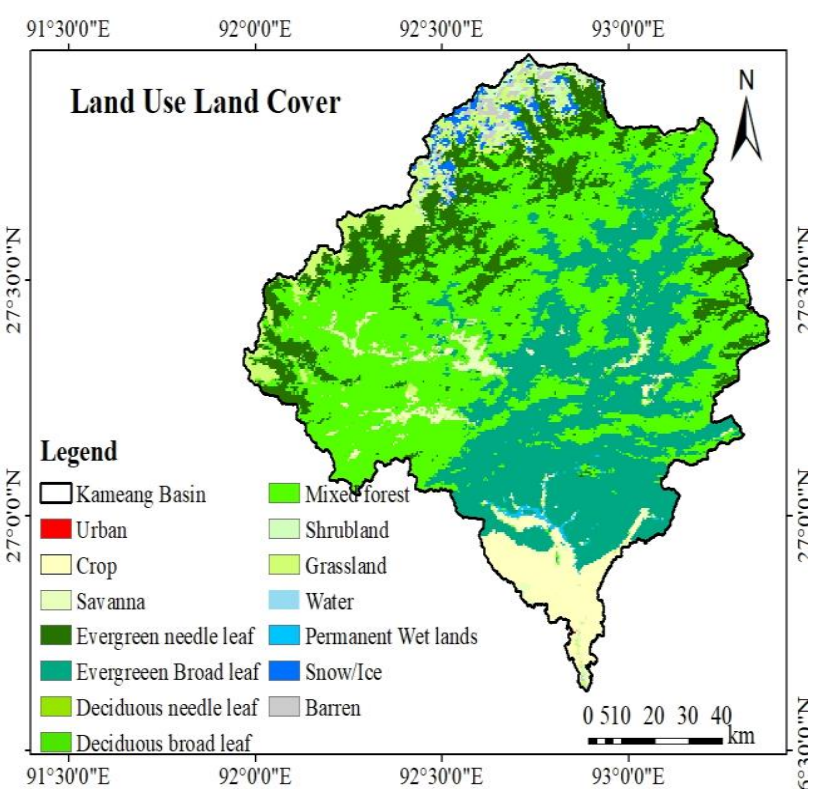

Figure 3. Land Use Land Cover Map

\subsection{Model Setup}

The VIC model using the energy balance algorithm takes into account the heterogeneity of the surface. The study area is divided into a number of independent grids and considers the sub grid variability of vegetation classes and elevation profile, resulting into a more realistic computation of hydrological parameters. In our study, the river basin was divided into a grid resolution of $2.5 \mathrm{~km}$ and sub grid variability was introduced at $500 \mathrm{~m}$ elevation levels and as per vegetation classes independently.

VIC Hydrological model requires separate files for each grid containing the required parameters for hydrological analysis. A global control file specifies the run time parameters such as time step, output parameters etc. The model was executed at a 3-hour time interval from 1979 till 2010, with outputs being generated at daily time step from 1999 onwards, accounting for a 20 -year spin-up period.

The calibration of the model is an iterative process where the governing parameters are iterated to obtain the best possible match between the observed \& simulated discharge. The major governing parameters used are depth of soil layers \& three subsurface flow variables. Minor parameters use snow variables. Two criteria of Coefficient of Determination $\left(R^{2}\right) \&$ NashSutcliffe efficiency (NSE) were used to undertake model calibration.

\section{RESULTS \& DISCUSSIONS}

The study attempts to separate the hydrographs into two components mainly snowmelt \& all other sources.

\subsection{Hydrological Modelling}

The input files containing land use, soil, elevation \& meteorological parameters were applied to 3-layer VIC model, executed using default values. The model outputs were routed using a routing model (Lohmann, Nolte-Holube, and Raschke, 1996) at 5 locations namely Dirang (Dirang river), Tenga (Tenga River), Bichom, Seppa \& Bhalukpong (Location of CWC gauge). The routed output discharge was compared with observed discharge at Bhalukpong on a monthly basis. The pre calibration values of $\mathrm{R}^{2} \&$ NSE were obtained as $0.68 \& 0.6$ respectively. Figure 4 depicts pre-calibration scenario.
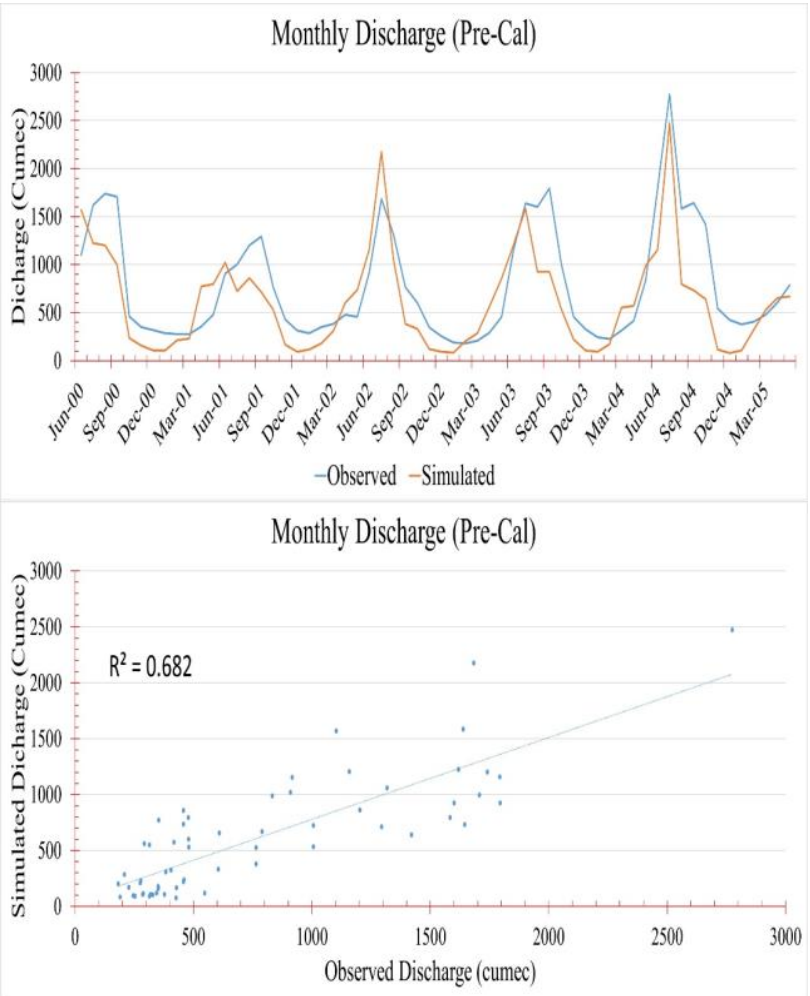

Figure 4. Pre Calibration Scenario

As the streamflow can be computed to a high accuracy in modelling process, the model parameters were adjusted during the calibration procedure. The parameter value as obtained are listed in table 2. Post calibration comparison showed a good agreement between observed \& Simulated values. The post calibration values of $\mathrm{R}^{2} \&$ NSE were obtained as 0.82 \& 071 respectively. Figure 5 depicts post-calibration scenario.

\begin{tabular}{|c|c|}
\hline Parameter & Value \\
\hline $\mathrm{b}$ & 0.2 \\
\hline $\mathrm{D}_{\mathrm{s}}$ & 0.5 \\
\hline $\mathrm{W}_{\mathrm{s}}$ & 0.5 \\
\hline Depth $(\mathrm{i}=1,2,3)$ & $0.1,2.3,1.5$ \\
\hline
\end{tabular}

TABLE 2. Model Parameters 


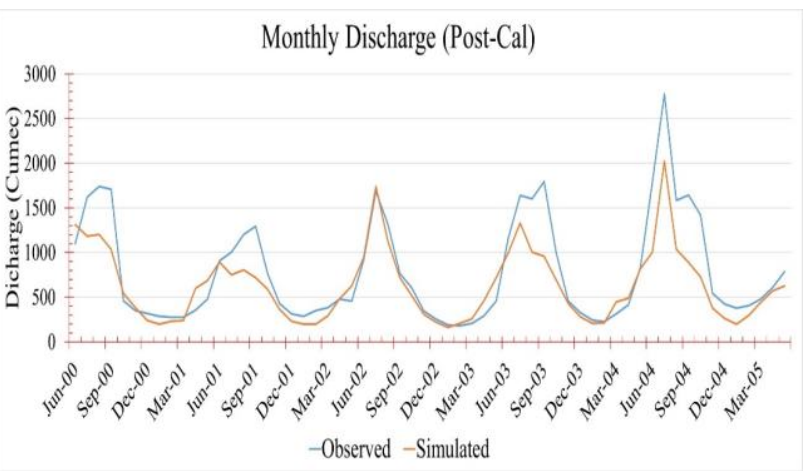

Monthly Discharge (Post-Cal)

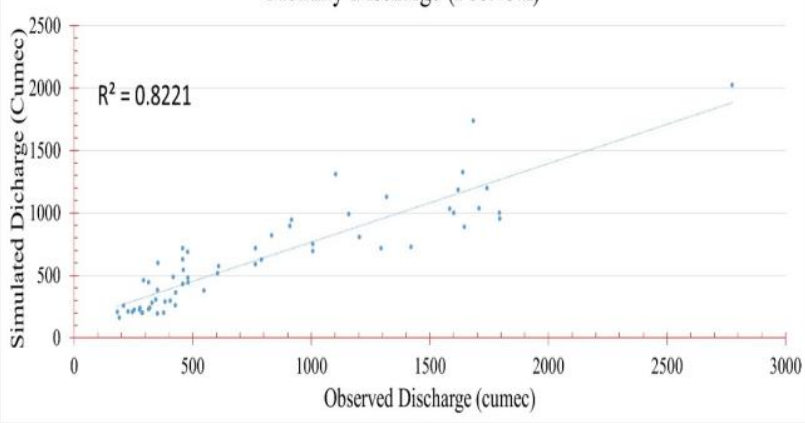

Figure 5. Post Calibration Scenario

As depicted in Figure 5, the agreement between simulated \& observed discharge is good. The over/under estimation of the discharge value is inherent to the simulation process. It may be noted that peak monsoon values are under estimated while low flow season (winter, pre-monsoon) is accurately depicted.

\subsection{Hydrograph Separation}

The independent results of simulated grids were processed depict status of streamflow \& its analysis with observed data and melt components. From the analysis of the discharge hydrographs, it is estimated that the discharge is dominated by rain water in monsoon season while the pre/post-monsoon season flow regime can be estimated to be comprised of mostly a constant groundwater discharge. The region is known for heavy rainfall, averaging peak rainfall of $425 \mathrm{~mm} /$ month during monsoon season. To calculate the volume of meltwater, the surface energy balance was calculated using energy balance parameters as obtained from simulations using VIC model at each grid cell level. Incoming shortwave \& longwave radiation flux, sensible heat flux, latent heat flux \& ground heat flux was directly taken from simulated output. The longwave emission at the surface was computed using surface temperature \& albedo values as calculated by the simulations. The melt runoff thus computed using per equation 2 (Siderius et al. ,2013) \& subsequently fraction of discharge due to melt water was obtained. The meltwater contribution on a decadal-monthly average for 5 locations as obtained is shown in Figure 6.

Melt Runoff $=\min \left\{\right.$ total runoff $*\left(\frac{\text { melt }}{\text { rain }+ \text { melt }}\right)$, Melt $\}$
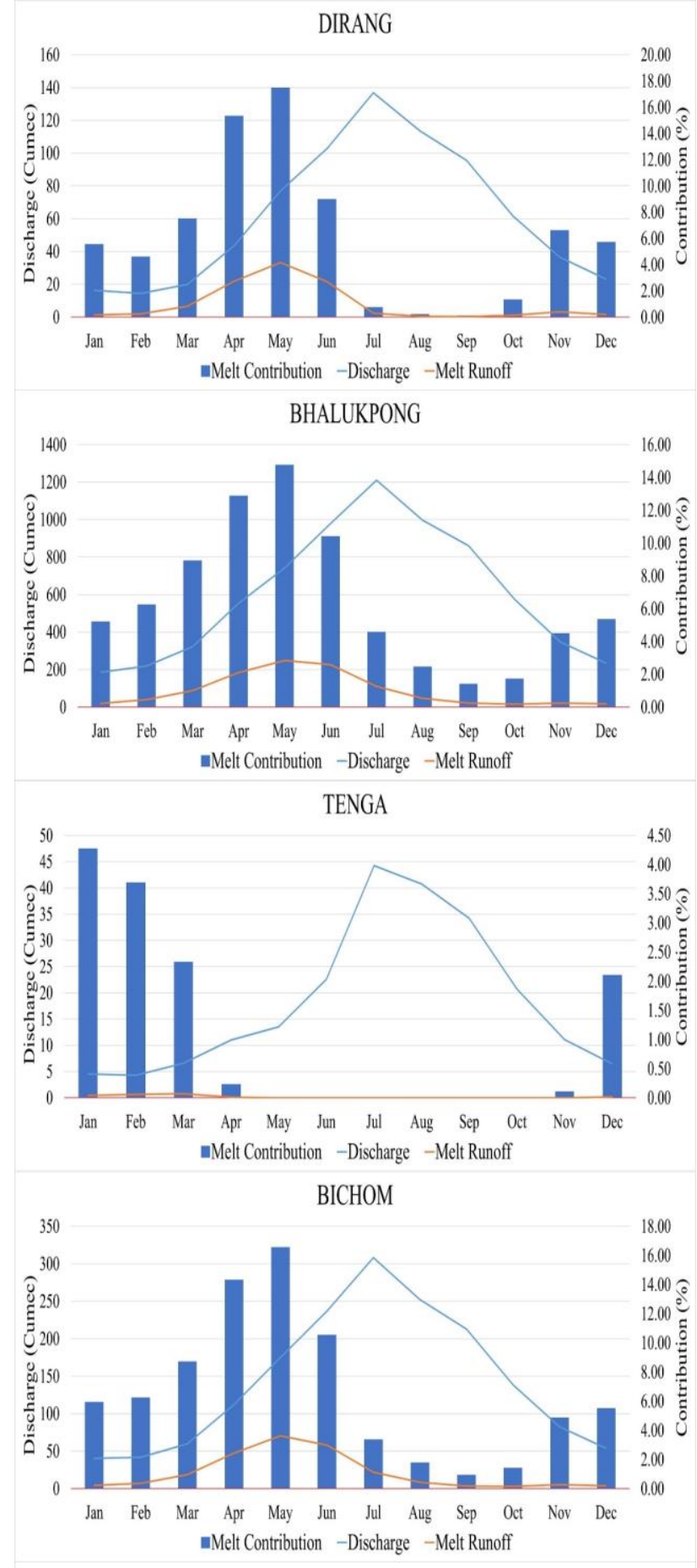

SEPPA

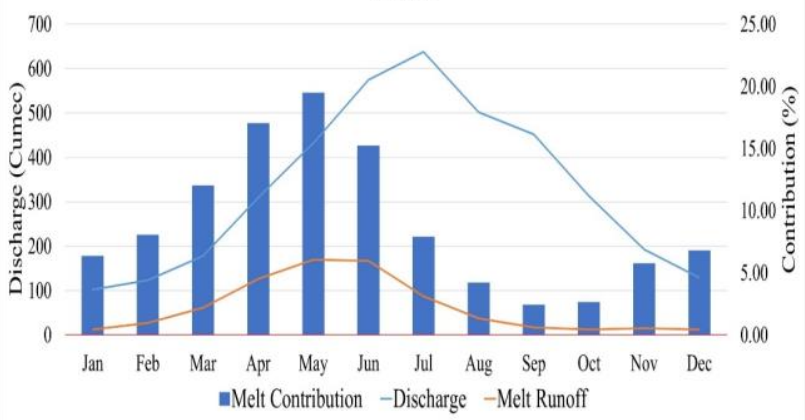

Figure 6. Meltwater Contribution 


\section{CONCLUSION \& FUTURE SCOPE}

Accurate assessment and planning of sustainable usage of water resources are important factors to be considered by policy makers. As per our estimates, streamflow this region is not dominated by snowmelt as witnessed in North Western Himalayan regions, rather dominated by monsoon driven streamflow. This work highlights the importance of identifying the flow components in Himalayan catchments using remote sensing and hydrological models. The spatio-temporal variability of hydrological fluxes and individual components of the flow have been highlighted in this study. These datasets as generated shall be useful for state \& central government water resources department, Hydro-electric companies \& NGO's for planning and assessment purposes.

In our study we estimate the maximum melt water contribution is estimated at $18 \%$ at peak melt season in month of May, reducing significantly as monsoon takes over then slightly increasing again in winters. This phenomenon can be explained using volumetric argument i.e. During winters the volume of melt discharge decreases along with the net discharge in the river, with the latter decreasing by a much larger factor relative to former. This phenomenon leads to increased values of fractional contribution of melt water to the stream flow as described in Figure 6.

Further improvements, specific to Eastern Himalayan region are required, in particular to the availability of ground data, which as of now is scarce. As the streamflow is monsoon dominated, further efforts shall be done to estimate the future discharge trends in a changing climate scenario. Kumar \& Dimri, 2018 estimate that the region will witness significant decrease in rainfall of up to $40 \%$ by end of the century w.r.t to baseline trends of 1979-2005 as shown in Figure 7, which is a cause of concern as it'll result in decreased streamflow in monsoon months \& will subsequently affect winter flows, which will affect water availability in the region affecting the local population as well as multiple hydro-power projects being developed in the region
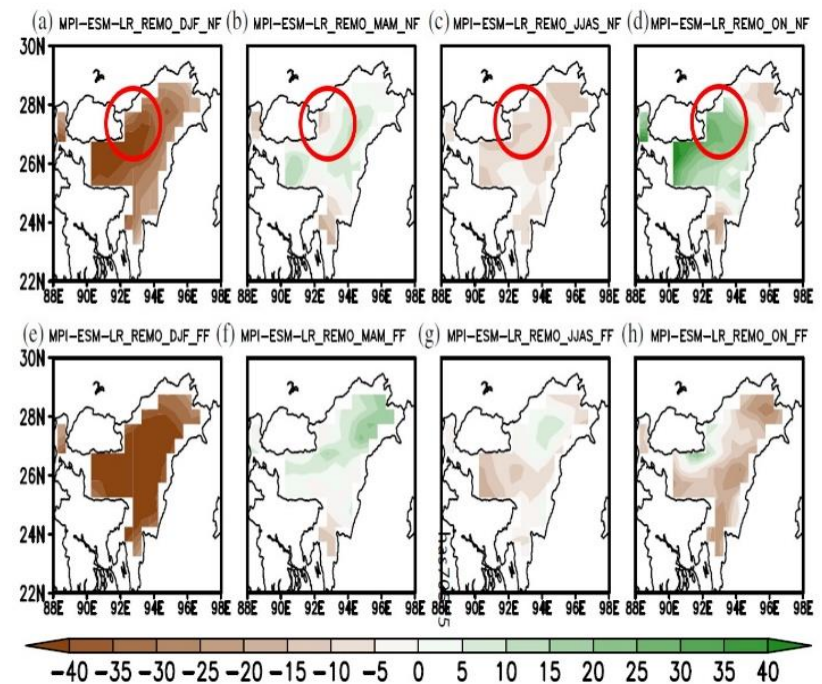

Figure 7. Change in precipitation Trends (a)-(d) : Near Future Prediction, 2020- 2050

(e)-(h) : Far Future Prediction, 2070 - 2099 (source: Kumar \& Dimri, 2018)
The author would like to acknowledge The Chair \& faculty members, Divecha Centre for Climate Change, Indian Institute of Science, Bengaluru for their kind support to complete this work. Also the author would like to mention the role of $\mathrm{B} \& \mathrm{BBO}, \mathrm{CWC}$ for providing the discharge data.

\section{REFERENCES}

Brown, M.E.; Ouyang, H.; Habib, S.; Shrestha, B.; Shrestha, M.; Panday, P.; Tszortziou, M.; Policelli, F.; Artan, G.; Giriraj, A.; Bajracharya, S.R. \& Racoviteanu, A. 2010. HIMALA: Climate Impacts on Glaciers, Snow, and Hydrology in the Himalayan Region. Mountain Research and Development, 30(4): 401-404.

Broxton, P.D., Zeng, X., Sulla-Menashe, D., Troch, P.A., 2014a: A Global Land Cover Climatology Using MODIS Data. J. Appl. Meteor. Climatol., 53, 1593»1605. Doi: http://dx.doi.org/10.1175/JAMC-D-13-0270.1

Chiphang, N., Bandyopadhyay, A., \& Bhadra, A. (2020). Assessing the Effects of Snowmelt Dynamics on Streamflow and Water Balance Components in an Eastern Himalayan River Basin Using SWAT Model. Environmental Modeling \& Assessment, 25(6), 861-883. https://doi.org/10.1007/s10666020-09716-8

Dimri, A.P., Bookhagen, B. Stoffel, M. and Yasunari, T. (Eds.), 2020. Himalayan Weather and Climate and their Impact on the Environment, (C) Springer Nature Switzerland AG 2020, 1st ed. 2020, XIV, 577 p. https://doi.org/10.1007/978-3-030-29684-1. ISBN 978-3-030-29683-4.

Immerzeel, W. W., \& Bierkens, M. F. P. (2012). Asia's water balance. Nature Geoscience. https://doi.org/10.1038/ngeo1643

Kumar,D \& Dimri, A.P. (2018), Regional climate projections for Northeast India: an appraisal from CORDEX South Asia experiment, Theor Appl Climatol (2018) 134:1065-1081 https://doi.org/10.1007/s00704-017-2318-z

Lettenmaier, D.P., 2001. Present and Future of Modeling Global Environmental Change: Toward Integrated Modeling,. In: T.M. Eds. and H. Kida (Editors), Macroscale Hydrology: Challenges and Opportunities, pp. 111-136.

Liang, X., 1994. A Two-Layer Variable Infiltration Capacity Land Surface Representation for General Circulation Models. Water Resour. Series TR140, Univ. of Washington, Seattle.

Liang, X., Lattenmaier, D.P., Wood, E.F. and Burgess, S.J., 1994. A simple hydrologically based model of land surface, water, and energy flux for general circulation models. Journal of Geophysical Research, 99(D7), pp. 14,415-14,428.

Liang, X., Lettenmaier, D.P. and Wood, E.F., 1996. Onedimensional Statistical Dynamic Representation of Subgrid Spatial Variability of Precipitation in the Two-Layer Variable Infiltration Capacity Model. J. Geophys. Res., 101(D16), pp. 21,403-21,422.

Lohmann, D., Nolte-Holube, R. and Raschke, E. (1996), A largescale horizontal routing model to be coupled to land surface 
parametrization schemes. Tellus A, 48: 708-721. Doi:10.1034/j.1600-0870.1996.t01-3-00009.x

Myneni, R., Knyazikhin, Y., Park, T. (2015). MCD15A2H MODIS/Terra+Aqua Leaf Area Index/FPAR 8-day L4 Global 500m SIN Grid V006 [Data set]. NASA EOSDIS Land Processes DAAC. doi: 10.5067/MODIS/MCD15A2H.006

Siderius, C., Biemans, H., Wiltshire, A., Rao, S., Franssen, WHP, Kumar, P., ...Collins, D.N., 2013, Snowmelt contributions to discharge of the Ganges, Science of The Total Environment, 46846, S93-S101. https://doi.org/10.1016/j.scitotenv.2013.05.084

Thakur, P. K., Aggarwal, S. P., Dhote P., Nikam, B. R., Garg, V., Bhatt, C. M., Chouksey, A. and Jha, A., 2019. Hydrometeorological Hazards Mapping, Monitoring and Modelling. Chapter 7 in Book, Remote Sensing of Northwest Himalayan Ecosystems Editors: Navalgund, R.R., Kumar, Senthil, Nandy, Subrata (Eds.), 1st ed. 2019, LII, 564 p. 301. DOI: $10.1007 / 978-981-13-2128-3$. 